live full, economically active lives will be condemned to a premature, preventable death.

\section{E G M Hoosen}

Paediatric Cardiology

Inkosi Albert Luthuli Central Hospital and

Department of Paediatrics

University of KwaZulu-Natal

Durban

\section{A M Cilliers \\ Division of Paediatric Cardiology \\ Chris Hani Baragwanath Hospital and \\ University of the Witwatersrand \\ Johannesburg}

\section{T Hugo-Hamman}

Constantiaberg Mediclinic

Cape Town, and

Stellenbosch University

Tygerberg, W Cape

\section{S C Brown}

Department of Paediatric Cardiology

Universitas Academic Hospital and

University of the Free State

Bloemfontein

\section{J B Lawrenson \\ L Zuhlke}

Paediatric Cardiology Services of the Western Cape Red Cross War Memorial and Tygerberg hospitals

University of Cape Town and Stellenbosch University

\section{J Hewitson}

Christiaan Barnard Division of Cardiothoracic Surgery

Red Cross War Memorial Children's Hospital and

University of Cape Town

\section{References}

1. Chopra M, Lawn JE, Sanders D, et al. Achieving the health Millennium Development Goals for South Africa: challenges and priorities. Lancet 2009;374:1023-1031.

2. Bradshaw D, Borne D, Nannan N. What are the leading causes of death among South African children? MRC Policy Brief No 3, December 2003. http://www.mrc.ac.za/policybriefs/childmortalitypd (accessed 30 March 2008)

3. Warnes CA, Liberthson R, Danielson GK, et al. Task force 1: the changing profile of congenital heart disease in adult life. J Am Coll Cardiol 2001;37(5):1170-1175.

4. Robertson KA, Volmink JA, Mayosi BM, et al. Towards a uniform plan for the control of rheumatic fever and rheumatic heart disease in Africa - the Awareness Surveillance Advocacy Prevention (A.S.A.P.) and rheumatic heart disease in Africa - the

5. Hoosen EGM, Cilliers AM, Hugo-Hamman CT, et al. Audit of paediatric cardiac services in South Hoosen EGM, Cilliers AM, H
Africa. SA Heart 2010;7:4-9.

Africa. SA Heart 2010;7:4-9.
Multiple authors. Fifth Report on the provision of services for patients with heart disease (United Multiple authors. Fifth Report on the provision
Kingdom). Heart 2002;88(suppl III): iiil-iiis9.

EACTS Congenital Heart Disease Committee. Optimal structure of a congenital heart surger department in Europe. Eur J Cardiothorac Surg 2003;24:343-351.

8. NHS congenital heart disease website. www.ccad.org.uk (accessed 18 December 2008).

9. Botto DL, Correa A, Erickson JD. Racial and temporal variations in the prevalence of heart defects. Pediatrics 2001;107:e32.

10. Neirotti R. Pediatric cardiac surgery in less privileged parts of the world. Personal View. Cardiol Young 2004;14:341-346.

11. Larrazabal LA, Jenkins KJ, Gauvreau K, et al. Improvement in congenital heart surgery in a developing country: the Guatemalan experience. Circulation 2007;116:1882-1887.

12. Global efforts for improving pediatric heart health. Report by Children's HeartLink. http://www. childrensheartlink.org (accessed 14 September 2009).

13. Stolf NAG. Congenital heart surgery in a developing country. A few men for a great challenge. Circulation 2007;116:1874-1875

14. Yacoub MH Establishing pediatric cardiovascular services in the developing world: A wake-up call. Circulation 2007;116:1876-1878

15. Hoosen EGM, Cilliers AM, Hugo-Hamman CT, et al Optimal paediatric cardiac services in South Africa - what do we need? SA Heart 2010;7:10-16.

16. Modernisation of paediatric cardiac services Report on the paediatric cardiology workshop meeting held at Strand Beach Hotel, Strand, 26-27 September 2002. http://www.doh.gov.za/mts/reports/ cardiology01.html (accessed 15 October 2008)

17. Pieper C. Addressing infant mortality. S Afr Med J 2005;95:492-495.

18. Bhagwanjee S, Scribante J. National audit of critical care resources in South Africa - unit and bed distribution. S Afr Med J 2007;97(12 Pt 3):1311-1314.

19. Kumar KR. The nuts and bolts of pediatric cardiac care for the economically challenged. Ann Pediatr Kumar KR. The nuts and bol

20. Hewitson J, Zilla P. Children's heart disease in sub-Saharan Africa: Challenging the burden of disease. SA Heart 2010;7:18-29.

\title{
Tuberculosis in prisons in sub-Saharan Africa - a potential time bomb
}

The World Health Organization (WHO) estimates that there are 10 million new cases of tuberculosis (TB) reported worldwide each year, and 1.7 million people die from the disease. ${ }^{1}$ The incidence of TB in sub-Saharan Africa (SSA) remains very high at over 300 new cases of TB per 100000 population in 2007. ${ }^{2}$ The TB epidemic in SSA is fuelled by the HIV epidemic, and up to $70 \%$ of adults with TB are co-infected with HIV. ${ }^{2}$ There are few data on drug-resistant TB from SSA, ${ }^{3}$ probably owing to poor TB programme performance, inadequate laboratory facilities for drug susceptibility testing (DST), and poor surveillance, data collection and reporting procedures. The WHO estimated that 69000 cases of MDR-TB emerged in 2008 in Africa, which is most probably an underestimate. ${ }^{1}$

The global focus on TB control is on early diagnosis and treatment of people in the community in high TB- and TB/HIV-endemic countries. People concentrated in confined situations, such as prisons, are important but often neglected reservoirs for TB transmission, and threaten those in the outside community. The European Academies of Sciences Advisory Committee on drug-resistant TB in Europe emphasised the poor TB control in prisons and the rapid spread of TB between prisoners and prison staff. ${ }^{4}$ Data from SSA prisons indicate a similar ominous situation in prisons in Africa. The prevalence of TB in SSA prisons is estimated to be $6-30$ times higher than that in the general population. ${ }^{5}$ The TB incidence rate in Zambian prisons is 5285 cases per 100000 inmates per year,which is about 10 times that of the outside population. ${ }^{6}$ A Center for Disease Control study of Botswanian prisons led to important recommendations, including active screening, contact investigation, reduction of transmission, and isoniazid preventative therapy for HIV-positive prison inmates and guards. ${ }^{7}$

$\mathrm{TB}$ in prisons threatens inmates and prison staff (wardens, cooks, clinical staff etc.), who are at particular risk of acquiring TB because of the conditions and working environment. Staff also interact with 
their families and community and may thus transmit the disease further. The restricted and confined conditions for prisoners and prison staff, poor nutrition, poor ventilation, stress and inadequate prison health services, conduce to the emergence and enhanced transmission of drug-resistant $\mathrm{TB}$, which may then spread into the community.

Alarming data from SSA show that the incidence of multi- and extensively drug-resistant tuberculosis (MDR-TB and XDR-TB) is increasing. ${ }^{7-9}$ Drug-resistant TB threatens all SSA national TB programmes because of problems with rapid identification, providing appropriate and effective treatment, and poor treatment outcomes. ${ }^{10,11}$ Disease surveillance and reporting of TB in prisons is often weak or non-existent, and the problem of TB and drug-resistant TB remains poorly defined. The WHO status report ${ }^{12}$ on TB in prisons reports an urgent need to ensure effective and efficient diagnosis and treatment of drug-resistant forms of TB. It recommends the development of an effective national TB programme to reduce the emergence of new drug-resistant strains of Mycobacterium tuberculosis, both inside and outside prisons, by effectively detecting and treating all MDR-TB cases. However, these guidelines have generally been ignored and not implemented in SSA, illustrating the large gap between the WHO recommendations and the reality in SSA prisons. Drug-resistant TB has been demonstrated in Zambian ${ }^{8}$ and Botswanian ${ }^{7}$ prisons. These countries have no data on drug-resistant TB in prisons or adequate drug resistance surveillance systems in place, 7 years after the studies. An article entitled Death and disease in Zimbabwe's prisons describes the terrible conditions faced by prisoners in SSA. ${ }^{9}$ Overcrowding, poor nutrition, poor sanitation, HIV infection and poor health care are obvious causes for the escalating death toll in Zimbabwe's prisons; TB is reported as the biggest killer disease.

Prisons in SSA have no proper isolation facilities to treat MDR/ XDR-TB. Such facilities are also scarce in district and referral hospitals, highlighting this wider problem. Since many XDR-TB patients are untreatable, where should prison inmates with XDR-TB be housed and what will happen to them? There is a great need to improve prison health services and to introduce rapid point-of-care diagnostics for $\mathrm{TB}$ and screening for drug resistance in prisons. ${ }^{13}$ Recommendations for infection control isolation of patients and protection of medical staff apply to all institutions but are not in place and not practical or applicable in SSA prisons. Isolation of prison inmates with active $\mathrm{TB}$ during the infectious phase is important for TB control but is impossible in the SSA prison infrastructure. The best method of infection control remains the early diagnosis of infectious cases and the prompt initiation of effective treatment to prevent the emergence of drug-resistant $\mathrm{TB}$.

Treatment of MDR/XDR-TB is expensive and will stress national health budgets. Without basic epidemiological data, it is difficult to justify investment to improve health services for prisoners in the face of competition for limited national budgets and resources by other important health problem areas. TB control will not be achieved in SSA until governments focus and take action on all aspects of the TB problem, which must include TB in confined institutions such as prisons. Other serious infectious diseases are also rapidly transmitted in prisons, including HIV, respiratory and skin infections, and STDs. Serious political and funding attention is required urgently ${ }^{14}$ to improve health services in SSA to prevent the potential time bomb of drug-resistant $\mathrm{TB}$ exploding and undermining the gains of $\mathrm{TB}$ control programmes.

\section{Justin O'Grady \\ Peter Mwaba \\ Matthew Bates}

Department of Infection

University College London Medical School

London, UK, and

University of Zambia-University College London Medical School (UNZA-UCLMS) Project

University Teaching Hospital

Lusaka, Zambia

\section{Nathan Kapata}

Alimuddin Zumla

University of Zambia-University College London Medical School (UNZA-UCLMS) Project

University Teaching Hospital

Lusaka

Corresponding author: A Zumla (a.zumla@ucl.ac.uk)

\section{References}

1. World Health Oganization. Multidrug and Extensively Drug-resistant TB (M/XDR-TB) - 2010 Global Report on Surveillance and Response. Geneva: World Health Oganization, 2010.

World Health Oganization. Global Tuberculosis Control - Epidemiology, Strategy, Financing. Geneva: World Health Oganization. Globa

W. Amor Y B, Nemser B, Singh A, Sankin A, Schluger N. Underreported threat of multidrug-resistant Amor Y B, Nemser B, Singh A, Sankin A, Schluger N. Underreported
tuberculosis in Africa. Emerging Infectious Diseases 2008;14:1345-1352.

tuberculosis in Africa. Emerging Infectious Diseases 2008; 14:1345-1352.
Fears R, Meulen V, Kaufmann S, et al. EASAC XDR-TB Report. London: European Academies Science Fears R, Meulen V, Kaufmann S, et al. EASAC XDR-TB Report. London: European
Advisory Council: Working group on XDR-TB in Eastern Europe, 2010: (in press).

5. Noeske J, Kuaban C, Amougou G, Piubello A, Pouillot R. Pulmonary tuberculosis in the Central Prison of Douala, Cameroon. East Afr Med J 2006;83(1):25-30.

6. Moszynski P. Zambian prisons "threaten public health" because of high rates of TB and HIV. Br Med J 2010; 340:2225.

Centers for Disease Control and Prevention. Rapid assessment of tuberculosis in a large prison system - Botswana, 2002. MMWR 2003;52: 250-252.

8. Habeenzu C, Mitarai S, Lubasi D, et al. Tuberculosis and multidrug resistance in Zambian prisons, 2000-2001. Int J Tuberc Lung Dis 2007;11: 1216-1220.

9. Alexander J. Death and disease in Zimbabwe's prisons. Lancet 2009; 373: 995-996.

10. Dheda K, Shean K, Zumla A, et al. Early treatment outcomes and HIV status of patients with extensively drug-resistant tuberculosis in South Africa: a retrospective cohort study. Lancet 2010;375: 1798-1807.

Migliori GB, Dheda K, Centis R, et al. Review of multidrug-resistant and extensively drug-resistant TB: Migliori GB, Dheda K, Centis R, et al. Review of multidrug-resistant and extensively drug-resistab.
global perspectives with a focus on sub-Saharan Africa. Trop Med Int Health 2010;15:1052-1066.

2. World Health Organization Regional Office for Europe. Status Paper on Prisons and Tuberculosis. World Health Organization
Copenhagen: WHO, 2007.

Copenhagen: WHO, 2007 .
13. Boehme CC, Nabeta P, Hillemann D, et al. Rapid molecular detection of tuberculosis and rifampin resistance. N Engl J Med 2010;363(11):1005-1015.

14. Marais BJ, Raviglione MC, Donald PR, et al. Scale-up of services and research priorities for diagnosis, management, and control of tuberculosis: a call to action. Lancet 2010;375: 2179-2191. 